\title{
Conjunctival melanoma: survival analysis in twenty-two Mexican patients
}

\author{
Melanoma conjuntival: análise de sobrevivência em vinte e dois pacientes mexicanos
}

Rosa Angélica Salcedo-Hernández ${ }^{1}$, Kuauhyama Luna-Ortiz ${ }^{1,2}$, Leonardo Saúl Lino-Silva ${ }^{3}$, Ángel Herrera-Gómez ${ }^{1}$, Verónica Villavicencio-Valencia ${ }^{1}$, Miriam Tejeda-Rojas ${ }^{1}$, José F. CARrillo ${ }^{1}$

\begin{abstract}
Purpose: To describe the cases of conjunctival melanoma (CM) and report the disease-free interval (DFI) and overall survival (OS).

Methods: The charts of 22 patients who were admitted to two hospitals between 1985 and 2006 were reviewed for pertinent data, including demographics, site of involvement in the conjunctiva and sub-sites, surgical treatment, and adjuvant treatment.

Results: There were 10 (45.45\%) males and 12 (54.55\%) females. Mean age was 52.3 years. In this group, 15 patients (68.1\%) involved the bulbar conjunctiva, and 7 (31.9\%) involved the palpebral conjunctiva. Of the 22 patients, $72.72 \%$ had a history of conjunctival melanosis. The average tumor size was $20.4 \mathrm{~mm}$. Eight (36.36\%) patients underwent orbital exenteration, 2 (9.06\%) had enucleation, 5 (22.72\%) had wide excision of the lesion followed by radiotherapy, 2 (9.06\%) had orbital exenteration with neck dissection, and the remaining 5 patients (22.72\%) were considered adequately treated only with wide excision. Eight (36.36\%) patients received adjuvant treatment. Disease-free survival at 5 years was $51 \%$ and the overall survival at 5 and 10 years was $50 \%$ and $37 \%$, respectively.
\end{abstract}

Conclusion: Conjunctival melanoma is a rare entity. Tumor behavior is aggressive, and the optimal treatment is surgery with adjuvant therapy.

Keywords: Conjunctival neoplasms/surgery; Melanoma; Disease-free survival; Survival analysis

\section{RESUMO}

Objetivo: Descrever o intervalo livre de doença (DFI) e sobrevida global (OS) de pacientes com melanoma conjuntival (CM).

Método: Prontuários de 22 pacientes que foram internados em dois hospitais entre 1985 e 2006 foram revisados para dados pertinentes, incluindo dados demográficos, local de envolvimento na conjuntiva e outros locais de acometimento, tratamento cirúrgico e tratamento adjuvante.

Resultados: Dez (45,45\%) homens e 12 (54,55\%) mulheres foram selecionados. A média de idade foi de 52,3 anos. Em 15 pacientes $(68,1 \%)$ CM envolveu a conjuntiva bulbar, e em 7 (31,9\%) envolveu a conjuntiva palpebral. Dos 22 pacientes, 72,72\% tinham história de melanose conjuntival. O tamanho médio do tumor foi de $20,4 \mathrm{~mm}$. Oito (36,36\%) pacientes foram submetidos à exenteração orbital,2 (9,06\%) à enucleação, 5 (22,72\%) à ampla excisão da lesão seguida de radioterapia, $2(9,06 \%)$ à exenteração orbital com esvaziamento cervical e os restantes 5 pacientes $(22,72 \%)$ foram considerados adequadamente tratados apenas com excisão ampla. Oito (36,36\%) pacientes receberam tratamento adjuvante. Sobrevida livre de doença em 5 anos foi de $51 \%$ e sobrevida global em 5 e 10 anos foi de $50 \%$ e 37\%, respectivamente.

Conclusão: Melanoma conjuntival é uma entidade rara. Comportamento do tumor é agressivo, e o melhor tratamento é a cirurgia com terapia adjuvante.

Descritores: Neoplasias da conjuntiva/cirurgia;melanoma; Sobrevidalivre de doença; Análise de sobrevivência

\section{INTRODUCTION}

Ocular melanomas may arise from the eyelids, conjunctiva, and intraocular and orbital structures. Conjunctival melanoma and primary acquired melanosis (PAM) are pigmented lesions of the ocular surface. The incidence of conjunctival melanoma is low, estimated to occur in 0.2 to 0.5 cases/million of the Caucasian population. In a study of 4,836 patients with melanomas, $5.2 \%$ occurred in ocular structures, from which $85 \%$ occurred in the uvea and $4.8 \%$ in the conjunctiva ${ }^{(1,2)}$. However, in recent years there has been a significant increase in the number of cases of conjunctival melanoma in males, whereas the incidence of conjunctival melanoma has remained unchanged in females ${ }^{(1,3)}$. Conjunctival melanomas constitute $1 \%$ of the ocular melanomas and can originate from a PAM in 75\% of cases or develop de novo. Generally, it presents as a pigmented lesion although $30 \%$ are amelanic ${ }^{(4)}$. Twenty-six percent of cases with metastasis have been reported without nodular involvement. Other authors have reported lymph node disease in $41 \%$ of patients, with the most affected lymph nodes being pre-auricular ${ }^{(5)}$. The most significant factors reported for recurrence and metastatic disease are the presence of multi-focal tumors, myxoid cells, depth $>4 \mathrm{~mm}$, unfavorable locations (such as palpebral, caruncle, and cornea), scleral extension, advanced tumor node metastasis staging (TNM) and incomplete surgical excision ${ }^{(4,5)}$. Treatment options for conjunctival melanoma include surgical excision, excision combined with cryotherapy, radiotherapy, and topical chemotherapy ${ }^{(6,7)}$. Mortality at 10 years related to the tumor is between 10 and $30 \%{ }^{(3)}$. The purpose of this study is to report the natural history and results of treatment and follow-up of a series of cases with conjunctival melanoma recorded in a single Mexican oncology center.

\section{METHODS}

This is a retrospective study from 1985 to 2006. Thirty clinical charts of patients diagnosed with conjunctival melanoma were reviewed. Eight patients were excluded because they refused treatment. The cases analyzed had been subjected to biopsy in one center specia-
Submitted for publication: February 25, 2014

Accepted for publication: April 22, 2014

Study conducted at Instituto Nacional de Cancerología, México, D.F., México.

${ }^{1}$ Department of Head and Neck Surgery, Instituto Nacional de Cancerología, México, D.F., México.

División de Estudios de Posgrado, Universidad Nacional Autónoma de México (UNAM), México,

D.F., México.

${ }^{3}$ Departament of Anatomic Pathology, Instituto Nacional de Cancerología, México, D.F., México.
Funding: No specific financial support was available for this study.

Disclosure of potential conflicts of interest: None of the authors have any potential conflicts of interest to disclose.

Correspondence address: Leonardo Saúl Lino-Silva. Instituto Nacional de Cancerología, Anatomic Pathology. Av. San Fernando \#22, Col. Sección XVI, Tlalpan, México, D.F., 14080 E-mail: saul.lino.sil@gmail.com

Approval of the Institutional Review Board (IRB): This work was approved for The Comité de Ética del Instituto Nacional de Cancerología de México, although evaluation of the project by the Committee was not necessary. 
lizing in oncology (Instituto Nacional de Cancerología). They were subsequently surgically resected in our institution or arrived with a previous surgery for evaluation at our centers for a possible subsequent treatment. All patients had a diagnosis of conjunctival melanoma confirmed by histology, and all underwent liver function tests, chest $\mathrm{x}$-ray, and liver ultrasound to rule out distant metastases. Computed tomography $(\mathrm{CT})$ was performed when the exam results showed suspicious findings of local infiltration. The 2010 American Joint Committee on Cancer (AJCC) staging system was applied to patients in this series. Treatment with chemotherapy or radiotherapy was provided to selected patients (refer to the Results section). Overall, survival (OS) and disease free interval (DFI) curves were constructed using the Kaplan-Meier method and significant differences were analyzed with log-rank test.

\section{RESULTS}

The clinical-pathological data of the patients are summarized in table 1. We analyzed 22 patients; 10 (45.45\%) were men and twelve (54.55\%) were women. The average age of all patients at the time of diagnosis was 52.3 years (range: $16-82$ years). The mean follow-up time was 43.5 months (range: 2-218 months). All lesions were unilateral and had caused extensive damage (extension to ocular globe). Of the 22 patients, $72.72 \%$ had a previous history of melanosis. Fifteen lesions (68.1\%) involved the bulbar conjunctiva, and seven lesions (31.9\%) the palpebral conjunctiva. The limbus, fornix, and caruncle were involved in 9 (40.9\%), 8 (36.36\%), and 5 (22.72\%) cases, respectively. The mean tumor size was $20.4 \mathrm{~mm}$ (range: 3-70 mm). Alkaline phosphatase levels were elevated in 10 (45.45\%) cases.
All patients had a diagnosis of melanoma confirmed by histology. One patient (4.54\%) had bone infiltration. At clinical presentation, 6 patients (27.27\%) were staged as T1, 12 patients (54.55\%) as T3, and 4 patients (18.18\%) as T4. One patient (4.54\%) had metastatic disease at the time of diagnosis. The overall survival curves regarding $T$ classification are shown in figure 1. One case (4.54\%) had positive lymph nodes at presentation. The OS curve corresponding to the $\mathrm{N}$ factor is depicted in figure $2(p=0.004)$.

Eight (36.36\%) patients underwent orbital exenteration, 2 (9.06\%) had enucleation, 5 (22.72\%) had wide excision of the lesion followed by radiotherapy, 2 (9.06\%) had orbital exenteration with neck dissection, and the remaining 5 patients (22.72\%) were considered adequately treated only with wide excision.

Eight (36.36\%) patients received adjuvant treatment. Four patients (18.18\%) received chemo-radiotherapy, 2 patients (9.09\%) received chemotherapy alone, and 2 patients (9.09\%) received only radiotherapy. Disease-free survival at 5 years was $50 \%$ and overall survival rates at 5 and 10 years were 51 and 37\%, respectively ( $\mathrm{Fi}$ gures 3 and 4). The chemotherapy treatment supplied was based on carmustine, dacarbazine, and cisplatin, in the case of metastatic melanoma (two patients). The radiotherapy regimen consisted on hypo-fractionated stereotactic photon radiotherapy with 70 to $50 \mathrm{~Gy}$ delivered in five fractions in 7 days.

\section{DISCUSSION}

The incidence of conjunctival melanoma is low, with an estimated rate of 0.2 to 0.5 per million in the Caucasian population ${ }^{(8)}$. However, in recent years a significant increase in the number of cases of conjunctival melanoma has been reported in males with the inci-

Table 1. Clinical characteristics of twenty-two melanomas of the conjunctiva

\begin{tabular}{|c|c|c|c|c|c|c|c|}
\hline Case & Sex & Age & Follow up & Survival (months) & Treatment & Metastasis & Outcome \\
\hline 1 & Female & 16 & 2 & 2 & $\mathrm{OE}+\mathrm{ND}$ & Yes, nodal & DOD \\
\hline 2 & Male & 53 & 30 & 258 & $\mathrm{E}+\mathrm{CT}$ & No & DOD \\
\hline 3 & Female & 42 & 36 & 60 & WE + CTRT & No & DOD \\
\hline 4 & Male & 65 & 20 & 152 & $W E+C T$ & No & DFD \\
\hline 5 & Male & 47 & 32 & 60 & $W E+N D$ & No & DOD \\
\hline 6 & Female & 73 & 50 & 1 & OE & No & AWD \\
\hline 7 & Male & 27 & 258 & 32 & OE & No & DOD \\
\hline 8 & Female & 85 & 20 & 5 & $\mathrm{OE}+\mathrm{ND}$ & No & DOD \\
\hline 9 & Male & 55 & 66 & 17 & $\mathrm{OE}+\mathrm{RT}$ & No & AFD \\
\hline 10 & Female & 85 & 10 & 15 & $W E^{*}$ & No & DOD \\
\hline 11 & Male & 53 & 40 & 7 & $W E^{*}$ & No & AFD \\
\hline 12 & Female & 29 & 5 & 30 & $E$ & No & DOD \\
\hline 13 & Male & 70 & 20 & 12 & $W E^{*}$ & No & DFD \\
\hline 14 & Female & 50 & 32 & 7 & $\mathrm{OE}+\mathrm{RT}$ & No & AWD \\
\hline 15 & Male & 65 & 50 & 10 & $W E^{*}$ & No & DOD \\
\hline 16 & Female & 42 & 45 & 8 & $W E^{*}$ & Yes, bone & DOD \\
\hline 17 & Female & 56 & 30 & 9 & $\mathrm{OE}$ & No & DOD \\
\hline 18 & Male & 57 & 68 & 8 & $\mathrm{WE}+\mathrm{CTRT}$ & No & DOD \\
\hline 19 & Male & 60 & 61 & 30 & OE & No & AFD \\
\hline 20 & Female & 52 & 24 & 24 & $\mathrm{OE}+\mathrm{CTRT}$ & No & AWD \\
\hline 21 & Female & 40 & 34 & 58 & OE & No & AFD \\
\hline 22 & Female & 30 & 25 & 63 & WE + CTRT & No & AFD \\
\hline
\end{tabular}

$C C=$ cribriform carcinoma; $T N M=$ tumor, node metastasis staging; $A W D=$ alive with disease; $D O D=$ dead of disease; $A F D=$ alive free of disease; $O E=$ orbital exenteration; $E=$ enucleation; $\mathrm{WE}=$ wide excision; $\mathrm{ND}=$ neck dissection; $\mathrm{CTRT}=$ chemoradiotherapy. $\mathrm{CT}=$ chemotherapy. $\mathrm{RT}=$ radiotherapy.

${ }^{*}$ ) Performed out of our institution. 


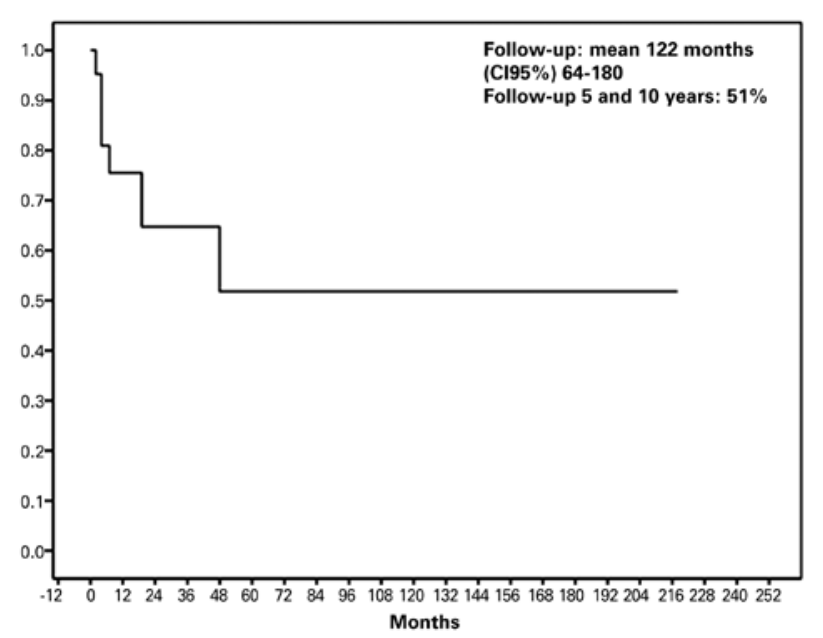

Figure 1. Disease free survival according to Kaplan-Meier. The mean follow up time was 122 months. The 5 -years disease free survival was $51 \%$.

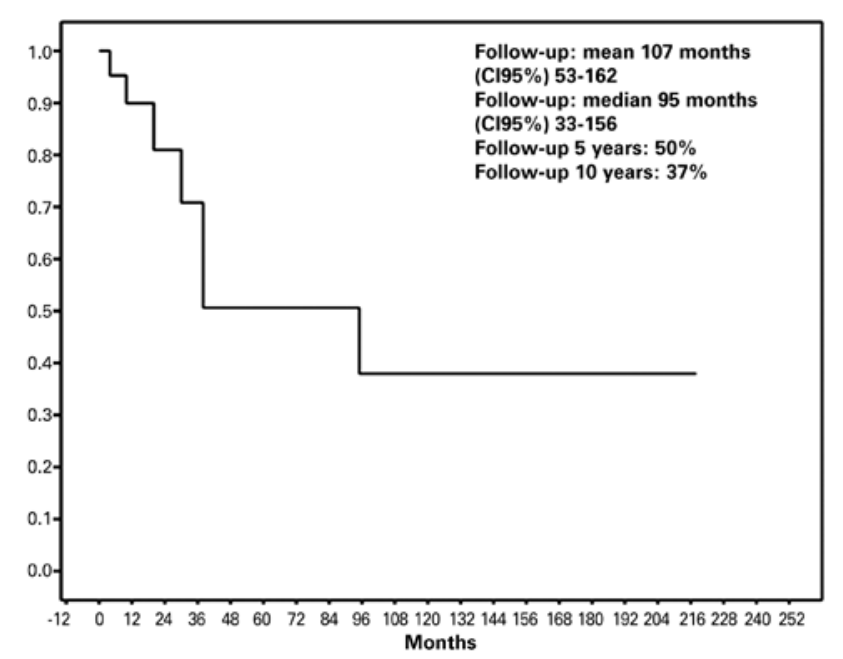

Figure 2. Overall survival according to Kaplan-Meier.The 5 -years overall survival was $50 \%$ and the 10 -years overall survival was $37 \%$. The mean follow up time was 107 months.

dence of conjunctival melanoma remaining unchanged in females ${ }^{(8)}$. In the present study, we report a male to female ratio of 1:1.2 (45.8\% males and $54.17 \%$ females). The age of presentation of conjunctival melanoma is usually in the fifth decade and it is only exceptionally observed in patients under 20 years of age, data which are in agreement with our results, with only one patient presented being under 20 years old ${ }^{(9,10)}$.

These tumors may arise de novo or from a pre-existing nevus, or more frequently from a PAM with proportions highly variable among different studies. Approximately 50\% to $75 \%$ originate from areas of PAM, $4 \%$ to $26 \%$ from conjunctival nevi and $18 \%$ to $39 \%$ arise de novo ${ }^{(8-11)}$. We found that 18 patients (75\%) had a previous history of melanosis. The most common presentation of conjunctival melanoma is a raised, irregular, unilateral pigmented area, brownish-black in color and most often without other associated symptoms. The presence of prominent and complex blood vessels is frequent ${ }^{(10)}$. In our study, all lesions were unilateral, and unlike the most common symptoms, they included a foreign body sensation and pain in the affected eye. Fifteen lesions (68.18\%) involved the bulbar conjunctiva and seven lesions (31.81\%) involved the palpebral conjunctiva. These data are in agreement with previous reports ${ }^{(8-10)}$.

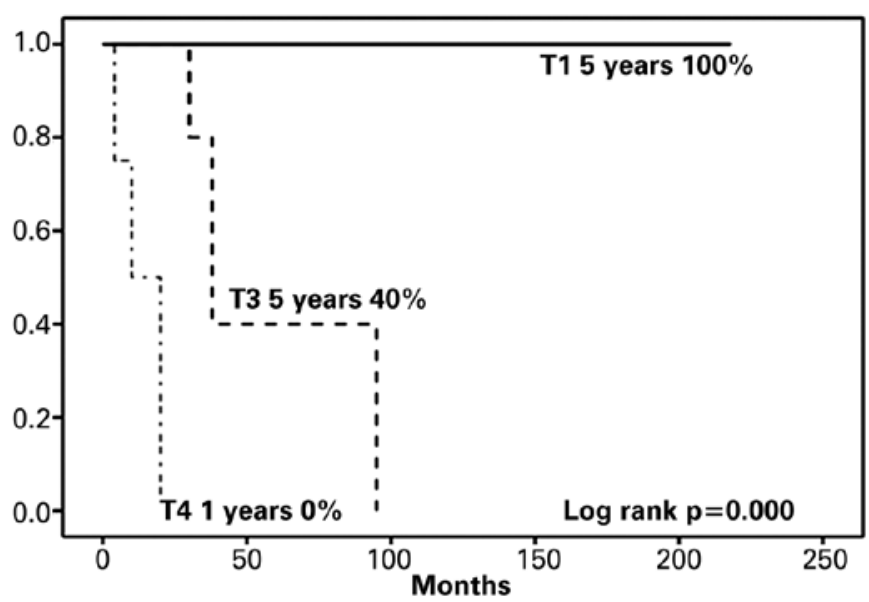

Figure 3. Survival by T stage, according to Kaplan-Meier. Tumors in advanced T stage show the worse prognosis. For T3 tumors, the 5 -years survival is $40 \%$ and $0 \%$ for T4 tumors.

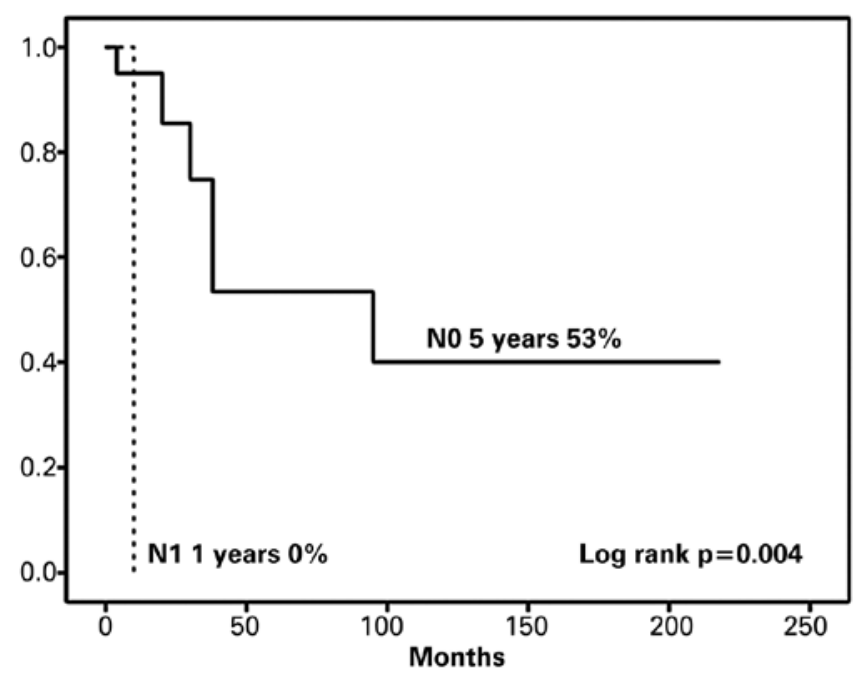

Figure 4. Survival by the $\mathrm{N}$ stage, according to Kaplan-Meier. Tumors without nodal metastasis showed a 5 -year survival of $53 \%$, but tumors with nodal metastasis.

The standard management of conjunctival melanomas is wide surgical excision, after which cryotherapy is applied to the normal residual margins of resection ${ }^{(11)}$. Patients treated initially with tumor excision alone had a statistically higher recurrence rate than those treated initially with excision and supplemental cryotherapy ${ }^{(12,13)}$. Surgical treatment of conjunctival melanoma has evolved to more conservative procedures. In the past, conjunctival melanoma implied an orbital exenteration ${ }^{(13)}$.

Prognosis of conjunctival melanoma depends on several factors previously reported in the literature: thickness $>4 \mathrm{~mm}$ is associated with a mortality rate 3.8 times higher than tumors measuring $<1 \mathrm{~mm}$ thick ${ }^{(8,10)}$. Lesions located on the palpebral or fornix conjunctiva have a poorer prognosis with a mortality rate 2.2 times higher than those located in the bulbar conjunctiva or in the limbus. Conjunctival melanoma of mixed cellular type has three times higher mortality than melanoma of fusiform cells ${ }^{(14)}$. Lymphatic invasion is associated with four times higher mortality rate. Amelanotic lesions demonstrate the most aggressive course and neither age nor gender is significant to the prognosis ${ }^{(10)}$. According to our results, the prognosis was unfavorable because of the characteristics of the tumor, which showed an average tumor size of $20.4 \mathrm{~mm}$ (range: $3-70 \mathrm{~mm}$ ), with $68.1 \%$ of them located in the extra-bulbar conjunctiva. 
As well as other treatment modalities such as cryotherapy, surgical techniques for management of this tumor have evolved slowly, being performed mainly at oncology centers ${ }^{(9)}$. In conjunctival melanoma, relatively narrow margins are obtained to preserve visual function. Orbital exenteration (removal of eyelids, eye, membranes, mucous membranes and orbital content) is reserved for patients with massive invasive melanomas and for tumors that originate in unfavorable sites (palpebral or fornix conjunctiva). This is mostly because the palpebral conjunctiva is closely attached to the tarsus by numerous septal connections and a minor surgical procedure would not give adequate margins. However, this procedure has not been shown to increase overall survival of these patients ${ }^{(14)}$. In our study, 8 (36.36\%) patients underwent orbital exenteration, 2 (9.06\%) had enucleation, $5(22.72 \%)$ had wide excision of the lesion followed by radiotherapy, $2(9.06 \%)$ had orbital exenteration with neck dissection, and the remaining 5 patients (22.72\%) were considered adequately treated only with wide excision. Eight (36.36\%) patients received adjuvant treatment. Treatment with exenteration was indicated by the size and extent of the melanoma because these tumors were larger than those reported in the literature.

Our results show that 6 patients had a T1 tumor. All of them were treated with wide excision with no adjuvant treatment, and showed no recurrence after a long term survival. In figure 1, as well, the prognostic significance of the T classification of the tumor is demonstrated, which has been pointed out previously ${ }^{(15)}$. These findings raise the case against the indiscriminate use of orbital exenteration, which could be reserved for $\mathrm{T} 4$ and selected $\mathrm{T} 3 \mathrm{cases}$, since no real improvement in survival is obtained with this procedure. However, recently, other studies have found greater significance for multi-focality and status of surgical margins, which may require surgery that is more extensive and/or radiotherapy to achieve local control ${ }^{(16)}$. Therefore, our results show that the use of chemotherapy alone or combined with radiotherapy appears to give a survival benefit to our patients (not extensively analyzed because of the small number of patients of our series) and it helps to plan the surgical treatment with a less invasive approach.

It is estimated that $\sim 50 \%$ of patients present recurrence at 10 years ${ }^{(14)}$. A recent review set a survival rate at 5 and 10 years of $\sim 85 \%$ and $70 \%$, respectively ${ }^{(17)}$. Overall mortality reported in different studies is $\sim 25 \%{ }^{(10)}$. In this study, $18 \%$ of patients developed late cervical metastases, pre-auricular and sub-mandibular lymph nodes involvement in descending order. This is due mainly to the fact that lymphatic channels exist in all parts of the stroma of the conjunctiva and these nodes mainly drain these sites ${ }^{(18)}$. Of the total patient pool, $18.18 \%$ died because of melanoma metastases.

In this study, the disease-free survival at 5 years was $51 \%$ and overall survival at 5 and 10 years was $50 \%$ and $37 \%$, respectively. This is lower than reported in the literature because the tumor characteristics in our study had an unfavorable prognosis. While the primary treatment of eyelid and conjunctival tumors is frequently surgical, several forms of ophthalmic radiation therapy have also been used to treat these malignancies. The goal of radiation therapy is to eradicate the tumor burden in a manner that maintains visual function and preserves surrounding sensitive ocular tissues. Ophthalmic radiation may be used as a curative therapy, as adjuvant treatment following surgical excision, or as palliative therapy for advanced cases of eyelid and conjunctival tumors ${ }^{(18)}$. Some reports have mentioned that radiation therapy has not proved useful and generally results in the loss of the eye as a complication ${ }^{(17-19)}$. However, in our experience and in the experience of others ${ }^{(18-20)}$, the use of adjuvant therapy is being increased due the greater prevalence of limited (organ preservative) resections, with little, but useful, increase in survival and local control.

\section{CONCLUSION}

Conjunctival melanomas are rare lesions showing an aggressive local behavior. They most frequently originate from a primary acquired melanosis. Any pigmented lesion in the conjunctiva in adults should be evaluated properly in a way as to rule out melanoma. The most common location is the bulbar conjunctiva. Surgery remains the cornerstone of treatment, and in our study, we found some benefit from adjuvant therapy, and its usage could determine a less aggressive surgery. Five- and 10-year survival is reported as $85 \%$ and $70 \%$, respectively in tumors staged as T1-T2. This figure decreases to $30 \%$ in tumors classified in higher stages.

\section{REFERENCES}

1. Yu G. Hu D, McCormick S, Finger PT. Conjunctival melanoma: is it increasing in the United States? Am J Ophthalmol. 2003;135(6):800-6. Comment in: Am J Ophthalmol. 2003;136(6):1189-90; author reply 1190; Am J Ophthalmol. 2003;136(6):1190; author reply 1190-1.

2. Chang AE, Karnell LH, Menck HR. The National Cancer Data Base report on cutaneous and noncutaneous melanoma: a summary of 84,836 cases from the past decade. The American College of Surgeons Commission on Cancer and the American Cancer Society. Cancer. 1998:83(8):1664-78.

3. Burgués-Ceballos A, Saornil MA, García-Alvarez C, Lagarto EG. Pigmented conjunctival growing lesion in a teenager: nevus or melanoma? Can J Ophthalmol. 2013;48(6): e154-6.

4. Anastassiou G, Heiligenhaus A, Bechrakis N, Bader E, Bornfeld N, Steuhl KP. Prognostic value of clinical and histopathological parameters in conjunctival melanomas: a retrospective study. Br J Ophthalmol. 2002;86(2):163-7. Comment in: Br J Ophthalmol. 2002; 86(2):127.

5. Werschnik C, Lommatzsch PK. Long-term follow-up of patients with conjunctival melanoma. Am J Clin Oncol. 2002;25:248-55

6. Salazar Méndez R, Baamonde Arbaiza B, de la Roz Martín P, Parra Rodríguez T. [Treatment of conjunctival melanoma]. Arch Soc Esp Oftalmol. 2012;89(2):82-4. Spanish.

7. Aronow ME, Singh AD. Radiation therapy: conjunctival and eyelid tumors. Dev Ophthalmol. 2013;52:85-93.

8. Kurli M, Chin K, Finger PT. Whole-body 18 FDG PET/CT imaging for lymph node and metastasic staging of conjunctival melanoma. Br J Ophthalmol. 2008;92(4):479-82. Comment in: Br J Ophthalmol. 2008;92(4):443-5.

9. Grin JM, Grant-Kels JM, Grin CM, Berke A, Kels BD. Ocular melanomas and melanocytic lesions of the eye. J Am Acad Dermatol. 1998;38(5 Pt 1):716-30. Comment in: J Am Acad Dermatol. 2000:42(1 Pt 1):145.

10. Shields CL, Shields JA, Gündüz K, Cater J, Mercado GV, Gross N, et al. Conjunctival melanoma. Risk factors for recurrence, exenteration, metastasis, and death in 150 consecutive patients. Arch Ophthalmol. 2000:118(11):1497-507. Comment in: Arch Ophthalmol. 2000; 118(11):1525-33.

11. Jakobiec FA, Rini FJ, Fraunfelder FT, Brownstein S. Cryotherapy for conjunctival primary acquired melanosis and malignant melanoma. Experience with 62 cases. Ophthalmology. 1988;95(8):1058-70.

12. De Potter P, Shields CL, Shields JA, Menduke H. Clinical predictive factors for development of recurrence and metastasis in conjunctival melanoma: A review of 68 cases. Br J Ophthalmol. 1993;77(10):624-30.

13. Fang ZJ, He WM. A fast growing conjunctival malignant melanoma. Chin Med J. 2013, 126(18):3593.

14. Farber M, Schutzer P, Mihm MC. Pigmented lesions of the conjunctiva. J Am Acad Dermatol. 1998;38(6 Pt 1):971-8. Comment in: J Am Acad Dermatol. 2000;42(1 Pt 1):145.

15. Char DH. Ocular melanoma. Surg Clin North Am. 2003;83(2):253-74.

16. Shildkrot Y, Wilson MW. Conjunctival melanoma: pitfalls and dilemmas in management. Curr Opin Ophthalmol. 2010;21(5):380-6.

17. Kivelä T, Kujala E. Prognostication in eye cancer: the latest tumor, node, metastasis classification and beyond. Eye (Lond). 2013;27(2):243-52.

18. Missotten GS, Keijser S, De Keizer RJ, De Wolff-Rouendaal D. Conjunctival melanoma in the Netherlands: a nationwide study. Invest Ophthalmol Vis Sci. 2005;46(1):75-82.

19. Demirci H, Shields CL, Shields JA, Eagle RC Jr. Malignant melanoma arising from unusual conjunctival blue nevus. Arch Ophthalmol. 2000;118(11):1581-4.

20. Damato B. Heimann H. Personalized treatment of uveal melanoma. Eye (Lond). 2013; 27(2):172-9 